\title{
O Impacto do ICMS Substituição Tributária no Custo das Mercadorias Adquiridas pelo Comércio Varejista de Alimentos
}

\author{
José Jonas Alves Correia ${ }^{1}$, Filipe Emmanuel Alves da Silva ${ }^{2}$, Priscila Karla Ferreira da Silva ${ }^{3}$, Aldemar de Araújo Santos ${ }^{4}$
}

Resumo: Este trabalho teve por objetivo apresentar o impacto da substituição tributária do ICMS nos custos dos produtos adquiridos pelo comércio varejista. Para responder à questão de pesquisa e o objetivo proposto, utilizouse pesquisa documental e exploratória, onde para a análise dos dados, observou-se que as notas fiscais de aquisição de mercadorias oriundas de todas as regiões do país. Os dados foram coletados de uma empresa de atividade econômica de comércio varejista de alimentos em geral, cuja identidade foi mantida em anonimato nesta pesquisa, classificando neste aspecto a pesquisa como um estudo de caso. O estudo foi realizado no período de agosto a dezembro de 2015, na cidade de Juazeiro do Norte, Estado do Ceará. Percebeu-se com a pesquisa, que para o fisco, o mecanismo da substituição tributária proporciona uma arrecadação mais racional, o que provoca uma melhoria do controle fiscal e nos processos operacionais do ente fazendário e, que, em contrapartida, o fisco usa da transferência da responsabilidade tributária para concentrar a arrecadação em um número menor de contribuintes, sobre os quais recai o encargo de recolher todo o imposto incidente desde a primeira até a última etapa da operação com mercadorias, onerando os custos dos contribuintes, como é o caso das empresas das atividades de varejo e atacado de produtos alimentícios em geral.

Palavras-chave: ICMS. Substituição Tributária. Margem de Valor Agregado. Custo.

\section{The Impact of ICMS Tax Substitution in Cost of Goods Acquired by the Food Retail Trade}

\begin{abstract}
This study aimed to present the impact of the ICMS tax substitution in the cost of products purchased by the retail trade. To answer the research question and the proposed objective, it used documentary and exploratory research, where for the data analysis, it was observed that the invoices to purchase merchandise from all regions of the country. Data were collected from an economic activity company of retail trade of food in general, whose identity was kept anonymous in this research, ranking in this regard research as a case study. The study was conducted from August to December 2015 in the city of Juazeiro do Norte, Ceará State. It was noticed to the survey, which for the tax authorities, the tax replacement mechanism provides a more rational collection, which causes an improvement in the fiscal control and farm being operational processes and that, in return, the tax authorities use the transfer the tax liability to focus the collection on a me-nor number of taxpayers who bear the burden of collecting all the tax levied from first to the last stage of the transaction with goods, burdening taxpayer costs, as the case of companies in the retail and wholesale activities of food products in general.
\end{abstract}

Keywords: ICMS. Tax Substitution. Margin Value Added. Cost.

\footnotetext{
${ }^{1}$ Mestrando em Ciências Contábeis - Programa de Pós-graduação em Ciências Contábeis - PPGCC/UFPE.

E-mail: jhonnasallves@hotmail.com

${ }^{2}$ Mestrando em Ciências Contábeis - Programa de Pós-graduação em Ciências Contábeis - PPGCC/UFPE.

E-mail: felipeemmanuel@ hotmail.com

${ }^{3}$ Mestranda em Ciências Contábeis - Programa de Pós-graduação em Ciências Contábeis - PPGCC/UFPE.

E-mail: pri.kfs@gmail.com

${ }^{4}$ Professor do Departamento de Ciências Contábeis e Atuarias da Universidade Federal de Pernambuco - UFPE. Doutor em Tecnologias e

Sistemas de Informação - Universidade do Minho, Portugal. E-mail: aldemar@ufpe.br
} 
Id on Line Revista Multidisciplinar e de Psicologia

Id on Line Multidisciplinary and Psycology Journal

\section{Introdução}

No âmbito estadual, um dos impostos que mais sofrem alterações na legislação, visando uma otimização da arrecadaçãoé o Imposto sobre Operações Relativas à Circulação de Mercadorias e sobre Prestações de Serviços de Transporte Interestadual, Intermunicipal e de Comunicação (ICMS).

Neste contexto, foi criado o regime de substituição tributária do ICMS (ICMS-ST), no qual os produtos incluídos nesta modalidade são tributados antecipadamente, isto é, o imposto devido nas operações subsequentes já é arrecadado na primeira etapa de venda da mercadoria, facilitando a arrecadação de impostos e a fiscalização do cumprimento das obrigações fiscais pelos contribuintes, visto que o fisco concentra sua fiscalização em um número menor de contribuintes e não mais em todos os integrantes de uma cadeia de valor (BARRETO, 2013).

Conforme Galhardo (2010), o ICMS-ST foi criado inicialmentecom o intuito de diminuir a evasão fiscal, e sua eficácia foi notória de tal forma que atualmentetodos os Estados têm adotado essa sistemática de tributação, tendo em vista sua praticidade na fiscalização dos contribuintes.

Para Biava Júnior e Oyadomari (2010), os governos estaduais atualmente estão ampliando o rol de produtos abarcados pela técnica de tributação da substituição tributária no ICMS.Neste diapasão, o fisco cearense vem adaptando a sistemática da substituição tributária do ICMS ao âmbito interno, criando Leis, Decretos, Instruções Normativas e Notas Explicativas, para a regulamentação e aplicação da chamada substituição tributária interna.

Um dos casos é o Decreto ${ }^{\circ} 29.560$, de 27 de novembro de 2008, que regulamenta a Lei 14.237/2008, e trata de diversas atividades ali indicadas, dentre outras, das operações com comércio varejista de mercadorias em geral, com predominância de produtos alimentícios.

Este artigo tem como objeto de estudo, o comércio varejista de mercadorias em geral, com predominância de produtos alimentícios, conhecido como supermercados ou hipermercados. Esse segmento representauma das maiores fatias na economia brasileira. De acordo com dados da Associação Brasileira de Supermercados (ABRAS), o setor em vendas no ano de 2014, cresceu cerca de 2,24\% em comparação com o período anterior. 
Diante deste contexto, o artigo tem o objetivo de verificar analisar como a substituição tributária do ICMS do Decreto 29.560/2008 reflete nos custos de aquisição dos produtos das empresas do comércio varejista de mercadorias em geral.

Pressupondo-se que exista um reflexo negativo nos custos das mercadorias adquiridas pelo comércio varejista, após a aplicação da substituição tributária do ICMS pelo referido decreto, torna-se instigante pesquisar acerca desta temática pois interessa aos comerciantes e sobretudo aos consumidores a quem cabe pagar o preço final.

Conforme Oliveira (2011), com a inclusãocada vez mais de produtos no regime ICMSST, torna-se importante a abordagem de temas ligados a esse assunto.Para produzir esse trabalho e realizar tal análise foram escolhidos alguns produtos, de acordo com sua essencialidade e oriundos de regiões diferentes, sendo aindasubdivididos em três faixas conforme o anexo III do Decreto 29.560/2008: produtos com alíquota interna de 17\%; mercadorias com alíquota reduzida de $17 \%$ para $12 \%$; e por fim os produtos com redução de 17\% para 7\%; e a partir dos dados levantados verificou-se o impacto do ICMS Substituição no custo de aquisição das referidas mercadorias.

O trabalho está dividido em cinco seções, sendo esta uma seção introdutória onde foi apresentado e contextualizado o problema de pesquisa e seu objetivo. Nas próximas seções serão apresentadas características referentes à substituição tributária (ST) e o decreto 29.560/2008, que trata da ST nas empresas atacadistas e varejistas de produtos alimentícios em geral. Os procedimentos metodológicos utilizados na pesquisa serão o alvo da terceira seção. Em seguida, serão apresentados a análise e discussão dos resultados, e por fim as considerações finais na quinta e última seção.

\section{Substituição Tributária do ICMS: Conceitos básicos}

Segundo a Constituição da República Federativa do Brasil de 1988 artigo 155, inciso II, o ICMS é definido como Imposto sobre Operações relativas à Circulação de Mercadorias e Sobre a Prestação de Serviços de Transporte Interestadual e Intermunicipal e de Comunicação. É um imposto instituído e implementado pela Lei Complementar 87/96 (Lei Kandir), consoante 
o Código Tributário Nacional ele é um imposto de competência dos Estados e do Distrito Federal, e cada unidade federativa tem seu próprio regulamento.

No Estado do Ceará o ICMS é regido e consolidado pelo Decreto 24.569/97 (RICMSCE), que regulamenta a Lei 12.670/1996 a qual dispõe acerca do ICMS. De acordo com a Lei Kandir e com o Convênio ICMS nº 81/93, asubstituição tributária é o regime pelo qual a responsabilidade pelo pagamento do ICMS na circulação de mercadorias e/ou prestações de serviços é atribuída a outro contribuinte, que não seja o contribuinte de fato.

Conforme Baratto (2007) trata-se de uma forma de recolhimento, no qual aobrigação principal (tributo) passa a ser do primeiro representante na cadeia de tributação, normalmente as indústrias ou os importadores.

Ainda na linha de raciocínio de Baratto (2007), a substituição tributária é uma forma diferenciada de recolhimento do imposto, ela foi criada quando determinadas mercadorias tinham o seu preço tabelado pelo governo e possuíam poucos fabricantes. Foi implantada porque se constatou que poucos fabricantes vendiam seus produtos a milhares de distribuidores e revendedores, sendo que esses últimos sonegavam ICMS. Assim, passaram a tributar os fabricantes, que por serem grandes e em pouco número, seriam, e são, facilmente fiscalizados.

Segundo Paula (2011), a retenção antecipada do imposto está cada vez mais difundida entre as autoridades fazendárias do Estado. Foi um meio encontrado pelos governos de aumentar a arrecadação sem ter que aumentar os recursos aplicados na físcalização, principalmente no que tange a utilização de recursos humanos. O Decreto $\mathrm{n}^{\circ} 24.569$, de 31 de julho de 1997, Regulamento do ICMS do Estado do Ceará (RICMS - CE), define em seu Artigo 431 e seguintes a responsabilidade no regime de substituição tributária:

\begin{abstract}
A responsabilidade pela retenção e recolhimento do ICMS, na condição de contribuinte substituto, poderá ser atribuída, em relação ao imposto incidente sobre uma ou mais operações ou prestações sejam antecedentes, concomitantes ou subsequentes, inclusive ao valor decorrente da diferença entre as alíquotas interna e interestadual, nas operações e prestações interestaduais que destinem bens e serviços para o consumidor final localizado neste Estado, que seja contribuinte do ICMS.
\end{abstract}

Vale salientar que a responsabilidade de que trata o art. 431 do RICMS - CE, é atribuída ao industrial, comerciante ou a outra categoria de contribuinte; ao produtor, extrator, gerador; ao contratante de serviço ou terceiro que participe da prestação de serviços de transporte interestadual e intermunicipal e de comunicação. 
Neste sentido, existem ainda algumas modalidades que são adotadasquando realizada uma operação com substituição tributária, como descreve o quadro 1.

\section{Quadro 1 - Operações da substituição tributária}

\begin{tabular}{|l|l|}
\hline Operações anteriores & $\begin{array}{l}\text { Nesta hipótese de substituição tributária, a legislação atribui à determinado } \\
\text { contribuinte a responsabilidade pelo pagamento do ICMS em relação às operações } \\
\text { anteriores. Nesta modalidade se encontra o diferimento do lançamento do imposto, } \\
\text { que consoante a Lei Kandirocorre quando a responsabilidade pelo recolhimento } \\
\text { do imposto devido pelo fornecedor (remetente) se transfere para o comprador } \\
\text { (adquirente) da mercadoria e, cumulativamente, adia-se o termo inicial do prazo } \\
\text { de recolhimento do imposto devido. }\end{array}$ \\
\hline Operações subsequentes & $\begin{array}{l}\text { A substituição tributária em relação às operações subsequentes caracteriza-se pela } \\
\text { atribuição à determinado contribuinte (normalmente o primeiro na cadeia de } \\
\text { comercialização, o fabricante ou importador) pelo pagamento do valor do ICMS } \\
\text { incidente nas subsequentes operações com a mercadoria, até sua saída destinada a } \\
\text { consumidor ou usuário final.Conforme a Lei Complementar 87/96 por ser uma } \\
\text { tributação antecipada não se tem o preço exato, assim, para o cálculo do valor do } \\
\text { ICMS, a legislação estabelece, por produto, um percentual de agregação Margem } \\
\text { de Valor Agregado (MVA) à base de cálculo. }\end{array}$ \\
\hline Operaçõesconcomitantes & $\begin{array}{l}\text { Esta espécie de substituição tributária caracteriza-se pela atribuição da } \\
\text { responsabilidade pelo pagamento do imposto a outro contribuinte, e não àquele } \\
\text { que esteja realizando a operação ou prestação de serviço, concomitantemente à } \\
\text { ocorrência do fato gerador. Nesta modalidade se encontra a substituição tributária } \\
\text { dos serviços de transportes de cargas. }\end{array}$ \\
\hline
\end{tabular}

Fonte: Elaboração própria.

Outro fator importante quando se trata de matéria de tributação é o contribuinte ou sujeito. Conforme Machado (2004), contribuinte em sentido amplo, abrange qualquer pessoa obrigada a uma prestação tributária, de qualquer espécie, ou seja, o sujeito passivo da obrigação tributária é a pessoa, natural ou jurídica foi obrigada ao seu cumprimento. Nestes aspectos, a substituição tributária apresenta dois tipos de contribuintes (quadro 2).

Quadro 2 - Tipos de contribuintes da substituição tributária

\begin{tabular}{|c|c|}
\hline Contribuinte Substituto & $\begin{array}{l}\text { É o responsável pela retenção e recolhimento do imposto incidente em } \\
\text { operações ou prestações antecedentes, concomitantes ou subsequentes, inclusive } \\
\text { do valor decorrente da diferença entre as alíquotas interna e interestadual nas } \\
\text { operações e prestações que destinem mercadorias e serviços a consumidor final. } \\
\text { Em regra geral, será o fabricante ou importador no que se refere às operações } \\
\text { subsequentes. }\end{array}$ \\
\hline Contribuinte Substituíd & $\begin{array}{l}\text { Conforme a Lei Kandir é aquele cuja legislação designa como realizador da } \\
\text { hipótese deincidência (fato gerador) e que tem o imposto devido relativo às } \\
\text { operações e prestações de serviços pagos pelo contribuinte substituto, ou seja, } \\
\text { sofre a retenção. }\end{array}$ \\
\hline
\end{tabular}

Fonte: Elaboração própria. 
Ainda em observação ao tratamento dado as operações com substituição tributária, a Lei Complementar $n^{\circ}$ 87/96 em seu artigo $8^{\circ}$, ao tratar do regime de sujeição passiva por substituição, determina que a Base de Cálculo (BC) sejao valor correspondente ao preço de venda a consumidor acrescido do valor do frete, IPI e demais despesas debitadas ao estabelecimento destinatário, bem como a parcela resultante da aplicação (sobre esse total) do percentual de valor agregado (margem de lucro). Esse percentual é estabelecido em cada caso de acordo com as peculiaridades de cada mercadoria, conforme a Lei Kandir.

$\mathrm{BC}=($ Valor mercadoria + frete + IPI + outras despesas $) \times$ margem de lucro

Conforme Biava Júnior e Oyadomari (2010) os critérios de fixação da base de cálculo da substituição tributária têm por objetivo prever o preço final da mercadoria ao consumidor final. Para tanto são utilizadas algumas regras de fixação de base de cálculo que variam de produto a produto, e cujas regras gerais estão determinadas no artigo $8^{\circ}$ da Lei Complementar 87/1996. 9

A Margem de Valor Agregado (MVA) será determinada com base em preços usualmente praticados no mercado, obtidos por levantamento, ainda que por amostragem ou através de informações e outros elementos fornecidos por entidades representativas dos setores, adotando-se a média ponderada dos preços coletados. De acordo com o artigo $8^{\circ}$ da Lei Complementar 87/1996, a mercadoria submetida ao regime de substituição tributária em operação interestadual terá a MVA estabelecida em convênio ou protocolo.

\section{DECRETO 29.560/2008: a substituição tributária no estado do Ceará}

O Decreto 29.560/2008trata da substituição tributária para todos os contribuintes do Estado do Ceará, cuja Classificação Nacional de Atividades Econômicas (CNAE) físcal principal esteja enquadrada nas atividades de comércio atacadistas e varejistas de produtos como alimentícios em geral, de higiene pessoal, escritório e papelaria, livros e jornais, doces, balas e bombons, dentre outros, conforme listado nos anexos I e II do referido decreto. Também 
Id on Line Revista Multidisciplinar e de Psicologia

Id on Line Multidisciplinary and Psycology Journal

conhecido como decreto da "carga líquida" por utilizar os percentuais constantes no anexo III sobre a base de cálculo para se chegar ao valor do imposto a ser recolhido, foi criado para regulamentar a Lei 14.237/2008.

De acordo com o artigo $1^{\circ}$ do Decreto 29.560/2008, ficam todos os contribuintes enquadrados nas respectivas atividades econômicas constantes nos Anexos I e II, responsáveis na condição de substitutos tributários, pela retenção e recolhimento do Imposto sobre Operações Relativas à Circulação de Mercadorias e sobre Prestações de Serviços de Transporte Interestadual e Intermunicipal e de Comunicação (ICMS), devido nas operações subsequentes, até o consumidor final, quando da entrada ou da saída da mercadoria ou da prestação de serviço de comunicação, conforme o caso.

A base de cálculo para fins do cálculo do ICMS-ST na forma do Decreto 29.560/2008, conforme $\mathrm{o}$ artigo $2^{\circ}$ do referido dispositivo, será o equivalente à carga tributária líquida resultante daaplicação dos percentuais constantes do anexo III deste decreto, sobre o valor do documento fiscal relativo às entradas demercadorias, incluídos os valores do IPI, frete e carreto, seguro e outros encargos transferidos ao destinatário, conforme estabelecido na tabela 1 para as empresas varejistas.

Tabela 1- Carga líquida conforme origem da mercadoria

\begin{tabular}{lcc}
\hline & $\begin{array}{l}\text { Região Norte, Nordeste, Centro Oeste } \\
\text { e Estado do Espírito Santo }\end{array}$ & $\begin{array}{l}\text { Regiões Sul e Sudeste, exceto Estado do } \\
\text { Espírito Santo }\end{array}$ \\
\hline Cesta Básica 7\% & $3,46 \%$ & $5,52 \%$ \\
\hline Cesta Básica 12\% & $5,93 \%$ & $9,46 \%$ \\
\hline Demais - 17\% & $8,40 \%$ & $13,40 \%$ \\
\hline (Vinhos, Sidras) 25\% & $25,85 \%$ & $33,00 \%$ \\
\hline
\end{tabular}

Fonte: Decreto 29.560/2008, adaptado.

Nas operações internas, quando o adquirente dos produtos tributados na forma do decreto não se enquadrar nas atividades econômicas dos anexos I e II, poderá creditar-se do ICMS calculado mediante a aplicação da respectiva alíquota sobre o valor da operação, lançando-o diretamente no campo "Outros Créditos" do livro registro de apuração do ICMS, restabelecendo-se a cadeia normal de tributação (Art. $7^{\circ}, \S 3^{\circ}$ ). 
Id on Line Revista Multidisciplinar e de Psicologia

Id on Line Multidisciplinary and Psycology Journal

\section{Metodologia}

Com o intuito de responder à questão da pesquisa e atender ao objetivo proposto neste artigo, foi realizada uma pesquisa documental. Conforme Gil (2002, p. 46), a pesquisa documental apresenta vantagens, pois "há que se considerar que os documentos constituem fonte rica e estável de dados".

Por englobar um determinado estudo específico, relacionando fenômenos ou variáveis das características significativas, esta pesquisa também se classifica como descritiva. Assim, "a pesquisa descritiva configura-se como um estudo intermediário entre a pesquisa exploratória e a explicativa, ou seja, não é tão preliminar como a primeira, nem tão aprofundada como a segunda" (BEUREN, 2006, p. 81). No que concerne à abordagem do problema, esta pesquisa classifica-se como qualitativa.

Quanto ao delineamento da pesquisa, trata-se de um estudo de caso, o qual foi realizado numa empresa cuja identidade mantem-se no anonimato neste trabalho. $\mathrm{O}$ estudo foi realizado no período de agosto a dezembro de 2015, na cidade de Juazeiro do Norte, Ceará. As informações utilizadas para se chegar ao resultado desse trabalho, tais como valoresda operação, IPI, Frete e etc., foram extraídas de notas fiscais de compras fornecidas pelo grupo econômico da empresa, que atua no segmento varejista há mais de 50 anos.

Para melhor estruturar os dados comparativos, os produtos analisados (condicionar, detergente, sabão em pó, amaciante, xampu, sabão em barra) foram separados em três grupos distintos: os com alíquota Interna de 17\%; alíquota reduzida para 12\%; e alíquota reduzida para $7 \%$, conforme incisos I e II do artigo 41 do decreto 24.569/97, percentuais esses, aplicados em decorrência do princípio da seletividade, que está enraizado na Constituição Federal de 1988 e estabelece que o ICMS poderá ser seletivo em função da essencialidade das mercadorias e dos serviços (art. $155, \S 2^{\circ}$, inciso III).

\section{Resultados e Discussões}

Para fins comparativos, simulou-se uma situação em que a compra da mercadoria não estivesse incluída no regime de substituição tributária do ICMS no Estado do Ceará, ou seja, o 
Id on Line Revista Multidisciplinar e de Psicologia

Id on Line Multidisciplinary and Psycology Journal

regime normal de antecipação, conforme o artigo 767 do Decreto 24.569/1997, as mercadorias procedentes de outra unidade federada ficam sujeitas ao pagamento antecipado do ICMS sobre a saída subsequente.

Os primeiros dados foram analisados com mercadorias oriundas das Regiões Norte, Nordeste, Centro Oeste e do Estado do Espírito Santo, pois possuem a mesma carga líquida (alíquota). De acordo com a Tabela 2, se tem os valores que supostamente seriam pagos no regime de recolhimento normal do ICMS (antecipado), que é calculado aplicando a alíquota interna do Estado do Ceará sobre o montante da base de cálculo (valor mercadorias, fretes, IPI, seguros). Deste valor é subtraído o crédito de origem, que é calculado ao aplicar alíquotade origem constante na nota fiscal (Estado de aquisição) da mercadoria na base se cálculo.

Tabela 2 - Cálculo do ICMS no regime antecipado (normal)

\begin{tabular}{cccc}
\hline CÁLCULO & \multicolumn{2}{c}{ PRODUTOS COM ALÍQUOTA INTERNA 17\%, 12\%, 17\% } \\
\cline { 2 - 4 } & Condicionador & Detergente líquido 5L & Sabão em pó (1Kg) \\
\hline Valor unitário & 5,43 & 30,10 & 6,55 \\
\hline Alíquota do ICMS & $12 \%$ & $12 \%$ & $12 \%$ \\
\hline Valor do ICMS (Crédito) & 0,65 & 3,61 & 0,79 \\
\hline V. ICMS Antecipado & 0,27 & 1,07 & 0,14 \\
\hline Custo total & $\mathbf{5 , 1 6}$ & $\mathbf{2 9 , 0 4}$ & $\mathbf{6 , 4 1}$
\end{tabular}

Fonte: Valores extraídos de notas fiscais da Unilever Brasil Ltda. (PE); e alíquotas do RICMS-CE.

Para encontrar o valor do ICMS substituição exposto na tabela 3. Este é calculado ao aplicar sobre o valor das mercadorias, fretes, seguros, IPI, quando houver, a margem de valor agregado estabelecida no decreto, para então formar a base de cálculo do ICMS-ST, daí aplicase a carga líquida conforme expõe a tabela 1.

Tabela 3 - Cálculo do ICMS no regime substituição tributária

\begin{tabular}{cccc}
\hline CÁLCULO & \multicolumn{2}{c}{ PRODUTOS COM ALÍQUOTA INTERNA 17\%, 12\%, 17\% } \\
\cline { 2 - 4 } & Condicionador & Detergente líquido 5L & Sabão em pó (1Kg) \\
\hline Valor unitário & 5,43 & 30,10 & 6,55 \\
\hline Alíquota do ICMS & $12 \%$ & $12 \%$ & $12 \%$ \\
\hline Valor do ICMS (Crédito) & 0,65 & 3,61 & 0,79 \\
\hline V. ICMS Substituição & 0,46 & 1,78 & 0,23 \\
\hline Custo total & $\mathbf{5 , 8 9}$ & $\mathbf{3 1 , 8 8}$ & $\mathbf{6 , 7 8}$
\end{tabular}

Fonte: Valores extraídos de notas fiscais da Unilever Brasil Ltda. (PE); e alíquotas do RICMS-CE. 
Com o cálculo do ICMS-ST elucidado na tabela 3, percebe-se um valor maior arrecadado por esta modalidade de recolhimentodo ICMS. No entanto, esse valor é refletido nos custos dos produtos que de certa forma impactará na formação do preço de venda dos produtos. Como visto na tabela 2, os custos totais dos produtos têm uma redução, haja vista, o valor do imposto a ser pago por antecipação é abatido no valor do custo unitário do produto. Já a tabela 3 tem-se os valores que foram efetivamente recolhidos pelo estabelecimento varejista pelo regime de substituição tributária, o valor do ICMS-ST é adicionado ao custo do produto, majorando ainda mais o seu valor.

A tabela 4 mostra as apurações dos impostos pelo regime de antecipação e pela substituição tributária, salientando o impacto do ICMS-ST nos custos dos produtos.

Tabela 4 - Imposto pago a maior

\begin{tabular}{cccc}
\hline CÁLCULO & \multicolumn{3}{c}{ PRODUTOS } \\
\cline { 2 - 4 } & Condicionador & Detergente líquido 5L & Sabão em pó $(1 \mathrm{Kg})$ \\
\hline V. Subst.Tributária & 0,46 & 1,78 & 0,23 \\
\hline V. ICMS Antecipado & 0,27 & 1,07 & 0,14 \\
\hline Diferença & 0,18 & 0,72 & 0,09 \\
\hline Imposto pago a maior $(\mathbf{\%})$ & $\mathbf{4 1 , 3 \%}$ & $\mathbf{3 9 , 9 \%}$ & $\mathbf{3 9 , 1 \%}$
\end{tabular}

Fonte: Elaboração própria, baseada nas tabelas 2 e 3.

Conforme se observa na Tabela 4, há um aumento considerável no custo dos produtos após confrontar as duas formas de tributação do ICMS, o que nos permite numa análise inicial, verificar que a substituição tributária encarece as mercadorias.

Por ser uma organização que vende no atacado e varejo, a mesma possui uma rotatividade dos estoques alta, pois a empresa faz aquisição de todas as regiões do país e as vezes até importa alguns produtos. Neste contexto, as tabelas 5 e 6 explicam apuração dos custos com mercadorias oriundas das regiões Sul e Sudeste (exceto Espirito Santo), estas regiões transferem um crédito de origem de ICMS de 7\%. 
Id on Line Revista Multidisciplinar e de Psicologia

Tabela 5 - Cálculo do ICMS no regime antecipado (normal)

\begin{tabular}{cccc}
\hline CÁLCULO & \multicolumn{2}{c}{ PRODUTOS COM ALÍQUOTA INTERNA 17\%, 12\%, } \\
\cline { 2 - 4 } & Amaciante & Xampu 400 Ml & Sabão em barra \\
\cline { 2 - 4 } Valor unitário & 13,32 & 5,31 & 3,50 \\
\hline Alíquota do ICMS & $7 \%$ & $7 \%$ & 0,25 \\
\hline Valor do ICMS (Crédito) & 0,93 & 0,37 & 0,15 \\
\hline V. ICMS Antecipado & 1,33 & 0,37 & $\mathbf{3 , 3 5}$
\end{tabular}

Fonte: Valores extraídos das notas fiscais das empresas: Diversey Brasil Ltda (SP). L'oreal Brasil Ltda (RJ) e Química Amparo Ltda (SP); e alíquotas do RICMS - CE.

Foi supostamente levantado na Tabela 5, como seria o custo dos produtos adquiridos da região Sul e Sudeste caso o ICMS fosse recolhido como antecipado. Por sua vez, a tabela 6, traz o cálculo do recolhimento pelo regime de substituição tributária, que foi a real situação de recolhimento do imposto. Os cálculos são iguais os estabelecidos nas tabelas 2 e 3 .

Tabela 6 - Cálculo do ICMS no regime substituição tributária

\begin{tabular}{cccc}
\hline CÁLCULO & \multicolumn{2}{c}{ PRODUTOS COM ALÍQUOTA INTERNA 17\%, 12\%, } \\
\cline { 2 - 4 } & Amaciante & Xampu 400 Ml & Sabão em barra \\
\hline Valor unitário & 13,32 & 5,31 & 3,50 \\
\hline Alíquota do ICMS & $7 \%$ & $7 \%$ & $7 \%$ \\
\hline Valor do ICMS (Crédito) & 0,93 & 0,37 & 0,25 \\
\hline V. ICMS Substituição & 1,78 & 0,50 & 0,19 \\
\hline Custo total & $\mathbf{1 5 , 1 0}$ & $\mathbf{5 , 8 1}$ & $\mathbf{3 , 6 9}$
\end{tabular}

Fonte: Valores extraídos das notas fiscais das empresas: Diversey Brasil Ltda (SP). L'oreal Brasil Ltda (RJ) e Química Amparo Ltda (SP); e alíquotas do RICMS - CE.

Por fim, na Tabela 7, tem-se a diferença entre o que foi pago pelo regime de substituição tributária e o que seria pago no regime normal do ICMS (antecipado), com operações de mercadorias oriundas das regiões sul e sudeste. 
Id on Line Revista Multidisciplinar e de Psicologia

Id on Line Multidisciplinary and Psycology Journal

Tabela 7 - Imposto pago a maior

\begin{tabular}{cccc}
\hline CÁLCULO & \multicolumn{3}{c}{ PRODUTOS } \\
\cline { 2 - 4 } & Amaciante & Xampu 400 Ml & Sabão em barra \\
\hline V. Subst. tributária & 1,78 & 0,50 & 0,19 \\
\hline V. ICMS Antecipado & 1,33 & 0,37 & 0,15 \\
\hline Diferença & 0,45 & 0,13 & 0,04 \\
\hline Imposto pago a maior $(\%)$ & $\mathbf{2 5 , 3 \%}$ & $\mathbf{2 6 , 0 \%}$ & $\mathbf{2 1 , 1 \%}$
\end{tabular}

Fonte: Elaboração própria, baseada nas tabelas 5 e 6.

Percebe-se que a substituição tributária incidente sobre mercadorias de qualquer região do país irá encarecer os custos dos produtos, diferentemente se estes fossem recolhidos pelo ICMS antecipado no momento da entrada interestadual no Estado do Ceará.

Para fins comparativos, os resultados obtidos foram evidenciados graficamente. No gráfico 1 tem-se os produtos oriundos das Regiões Norte, Nordeste e Centro Oeste. Observa-se que a substituição tributária do ICMS onera o custo dos produtos adquiridos, nesse caso, especificamente o detergentelíquido tem o maior aumento relativo, em comparação aos demais produtos.

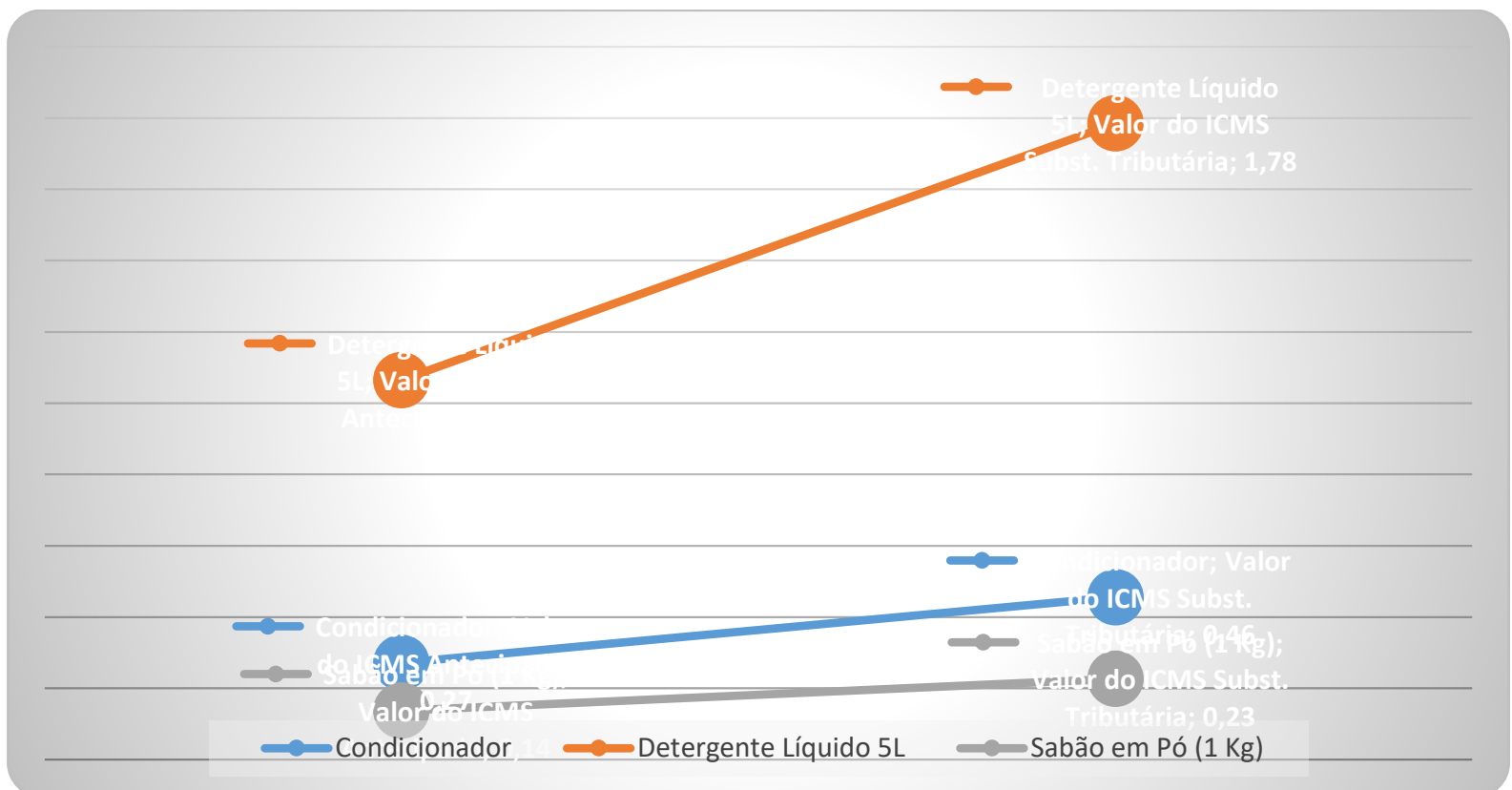

Gráfico 1 - Comparativo de aquisição de mercadorias nas regiões N, NE e CO.

Fonte: Elaboração própria 
Id on Line Revista Multidisciplinar e de Psicologia

Id on Line Multidisciplinary and Psycology Journal

O gráfico 2 traz os produtos oriundos das Sul e Sudeste. Verifica-se que a substituição tributária do ICMS onera o custo dos produtos adquiridos, nesse caso, especificamente o produto amaciante teve o maior aumento relativo, em comparação aos demais produtos.

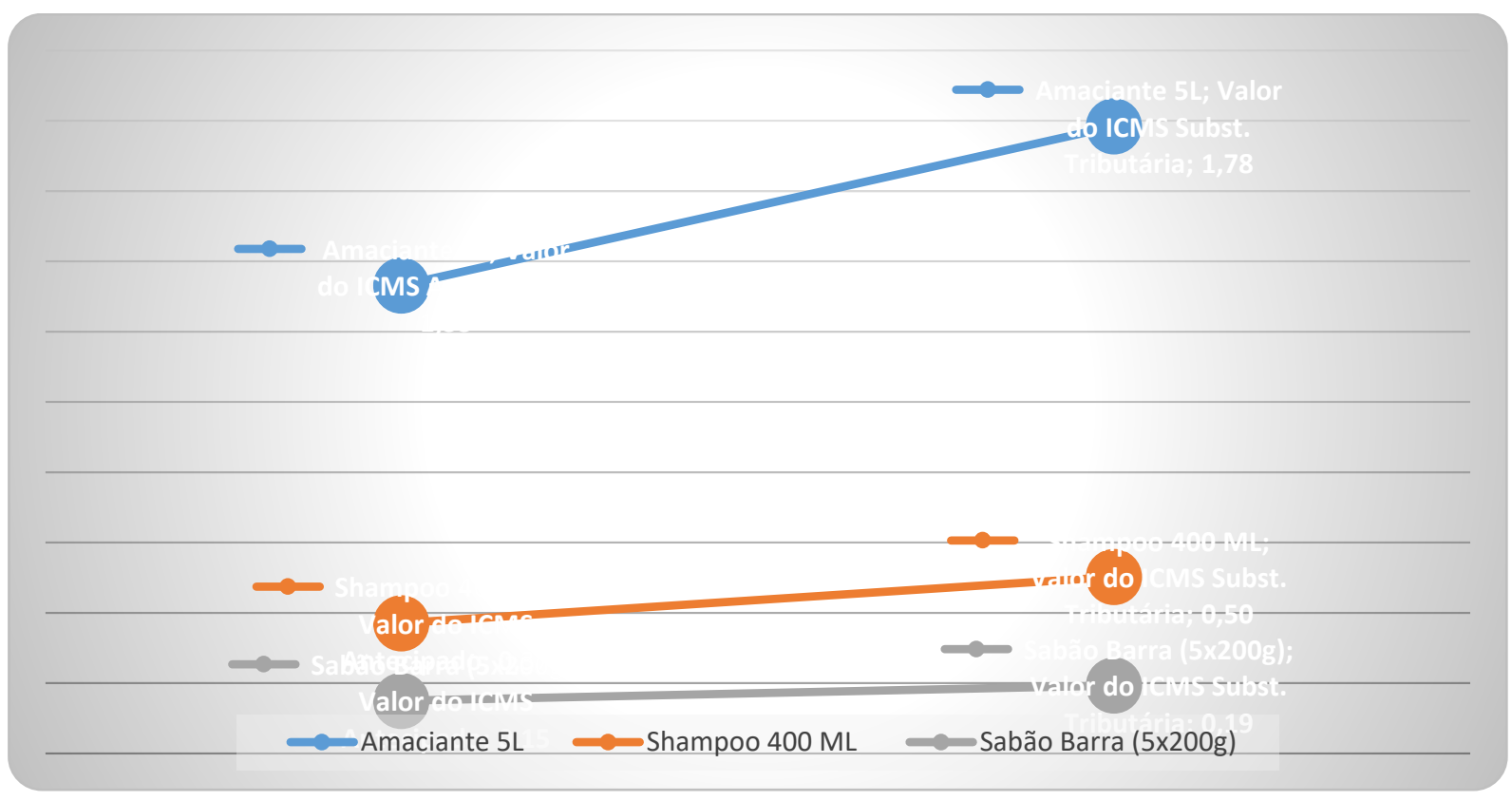

Gráfico 2 - Comparativo de aquisição de mercadorias nas regiões S e SE.

Fonte: Elaboração própria

Conforme se observa nas análises comparativas das tabelas e dos gráficos, a substituição tributária do ICMS, ora determinada pelo Decreto 29.560/2008, tem um alto índice de acréscimo nos custos das comercializações. Esse aumento será embutido no preço de venda das mercadorias, de forma que o consumidor final arque com o pagamento indireto dos impostos. Assim, enfatiza-se que o mecanismo da substituição tributária do ICMS propicia uma arrecadação com mais inteligência, que para o fisco indica uma melhoria do controle fiscal e na simplificação de processos operacionais.

\section{Considerações Finais}

O presente trabalho teve por objetivo analisar o impacto do ICMS substituição tributária no custo dos produtos adquiridos pelas empresas da atividade de comércios varejistas e atacadistas de mercadorias em geral, com predominâncias de produtos alimentícios 
Id on Line Revista Multidisciplinar e de Psicologia

Id on Line Multidisciplinary and Psycology Journal

(hipermercados) através do estudo de caso numa empresa do município de Juazeiro do Norte CE.

Observou-se que, a substituição tributária provoca um deslocamento da responsabilidade tributária, qualificando um terceiro como o responsável pelo pagamento em etapa que for mais conveniente para o órgão arrecadador. Assim, tem-se a projeção do recebimento em um instante futuro, presente ou anterior no lugar daquele que a própria lei definiu como sendo a matriz de cobrança, fator este principal da sistemática.

Diante disso, pode-se dizer que o mecanismo da substituição tributária proporciona uma arrecadação mais racional, o que provoca uma melhoria do controle fiscal e nos processos operacionais do ente fazendário. Em contrapartida, o fisco usa da transferência da responsabilidade tributária para concentrar a arrecadação em um número menor de contribuintes, sobre os quais recai o encargo de recolher todo o imposto incidente desde a primeira até a última etapa da operação com mercadorias, onerando os custos dos contribuintes com atividades de varejo e atacado de produtos em geral, durante a aquisição de mercadorias, conforme decreto 29.560/2008 estudado neste artigo.

Com o cálculo do ICMS-ST elucidado na tabela 3, percebe-se um valor maior arrecadado por esta modalidade de recolhimento do ICMS. No entanto, esse valor é refletido nos custos dos produtos que de certa forma impactará na formação do preço de venda dos produtos. Como visto na tabela 2 , os custos totais dos produtos têm uma redução, haja vista, o valor do imposto a ser pago por antecipação é abatido no valor do custo unitário do produto. Já a tabela 3 tem-se os valores que foram efetivamente recolhidos pelo estabelecimento varejista pelo regime de substituição tributária, o valor do ICMS-ST é adicionado ao custo do produto, majorando ainda mais o seu valor.

Neste diapasão, a pesquisa contribui no incentivo, de que os empresários e os profissionais contábeis realizem eficientemente um planejamento tributário, para assim, analisarem onde a substituição tributária mais afeta a empresa e procurar formas de minimizar estes efeitos.

Neste estudo de caso, constatou-se que nas aquisições oriundas das regiões sul e sudeste, há uma maior cobrança da substituição tributária, que impacta negativamente nos custos das mercadorias, refletindo na formação do preço do produto, que recai no consumidor final, último na cadeia produtiva 
Id on Line Revista Multidisciplinar e de Psicologia

Id on Line Multidisciplinary and Psycology Journal

Um destaque que vale atenção especial em relação à modalidade de arrecadação por substituição tributária, é que, embora esta prática proporcione certas vantagens tanto ao fisco quanto aos contribuintes, ainda há o que se questionar, em razão da falta de entendimento conceitual da temática, que de certa forma interferem nas atividades diárias dos profissionais contábeis. Dúvidas que, advindas da prática, mostram a incapacidade da legislação para levar em conta todos os detalhes que acontecem em cada uma das empresas, sejam elas indústrias, comércios ou prestadoras de serviços.

O artigo contribui academicamente por trazer conhecimento do fenômeno da tributação, pela construção de esclarecimentos práticos, que avaliaram teoricamente os efeitos financeiros das modalidades de tributação nas empresas, abrindo-se a possibilidade de desenvolvimento de pesquisas futuras, em entidades e em setores econômicos.

O trabalho limita-se ao estudo de caso e ao período de estudo. Sugerindo assim, para futuras pesquisas, estudar o fenômeno da substituição tributária do ICMS em outros decretos instituídos pelo fisco a outros setores econômicos.

\section{Referências}

ABRAS. Associação Brasileira de Supermercados. Índice Nacional de Vendas ABRAS. Disponível em: <http://www.abras.com.br/economia-e-pesquisa/indice-devendas/historico/>Acesso em: 25 de mar 2016.

BARATTO, G. Regime tributário do ICMS nas transações interestaduais - harmonização tributária ou autonomia estadual? Revista Paranaense de Desenvolvimento. Curitiba, n. 113, p. 9-30, jul./dez. 2007.

BARRETO, M. O impacto da substituição tributária progressiva do ICMS no preço de venda de produtos de informática do setor varejista no Estado de Santa Catarina. Trabalho de Conclusão de Curso (Bacharel em Ciências Contábeis). UNESC. Criciúma, 2013.

BEUREN, I. M. Como elaborar trabalhos monográficos em contabilidade: teoria e prática, 3 ed. São Paulo: Atlas, 2006.

BIAVA JUNIOR, R.; OYADOMARI, J. C. Impactos da Substituição Tributária do ICMS na Lucratividade e nos Custos Empresariais.Revista de Contabilidade da UFBA. Vol. 4, n $^{\circ}$ 2,2010 . 
Id on Line Revista Multidisciplinar e de Psicologia

Id on Line Multidisciplinary and Psycology Journal

BRASIL. Constituição da República Federativa do Brasil de 1988. Brasília, 05 outubro de 1988.

Ceará.

Decreto 24.569, de 31 de julho de 1997. Regulamento do ICMS do Estado do

Decreto $\mathrm{n}^{\circ}$ 29.560, de 27 de novembro de 2008. Regulamenta o regime de substituição tributária por contribuintes atacadistas e varejistas.

Lei Complementar no 87, de 13 de setembro de 1996 (Lei Kandir). Regula o ICMS entre os Estados.

Lei $n^{\circ}$ 12.670, de 27 de dezembro de 1996. Regula ICMS no Estado do Ceará.

Lei n⿳ 14.237, de 10 de novembro de 2008. Regulamento ICMS substituição tributária no Estado do Ceará.

GALHARDO, A. Esclarecimentos gerais sobre o regime da substituição tributária do ICMS. Disponível em: 〈http://ditizio.ecn.br/adv/txt/rste.pdf > Acesso em 25 abr 2016.

GIL, A. C. Como elaborar projetos de pesquisa. 4 ed - São Paulo: Atlas, 2002.

MACHADO, H. B. Curso de direito tributário. 23 ed. São Paulo: Malheiros, 2003.

OLIVEIRA, F.Impacto da substituição tributária do ICMS na formação do preço de venda em supermercados, dos produtos abrangidos por este tipo de tributação. Trabalho de Conclusão de Curso (Bacharel em Ciências Contábeis). UFRS, 2011.

PAULA, F. V.O impactodo regime de substituição tributária sobre o preço de produtos derivados do leite no Estado de São Paulo. Dissertação de Mestrado (Mestre em Economia Aplicada). Universidade de São Paulo. Piracicaba, 2011.

Como citar este artigo (Formato ABNT):

CORREIA, J.J.A.; SILVA, F.E.A.; SILVA, P.K.F.; SANTOS, A.A. O Impacto do ICMS Substituição Tributária no Custo das Mercadorias Adquiridas pelo Comércio Varejista de Alimentos. Id on Line Revista Multidisciplinar e de Psicologia, Nov-Dez. de 2016, vol.10, n.32, p. 54- 69. ISSN: 1981-1179.

Recebido: 07/11/2016

Aceito: $17 / 11 / 2016$ 